\title{
Teilnehmende Zeitgenossenschaft
}

\author{
Studien zum Protestantismus in den ethischen Debatten der Bundesrepublik \\ Deutschland 1949-1989 \\ Hrsg. v. Christian Albrecht u. Reiner Anselm
}

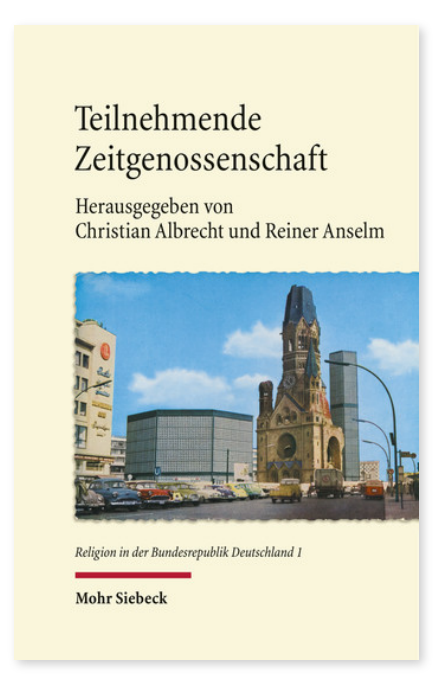

2015. XI, 416 Seiten. RBRD 1

ISBN 978-3-16-153913-8 DOI 10.1628/978-3-16-153913-8 eBook PDF 69,00€ ISBN 978-3-16-153630-4 Festeinband $69,00 €$
Ethische Debatten um Frieden und Freiheit, um Ehe und Familie, um soziale Gerechtigkeit und Schutz der Umwelt wurden rasch zu zentralen Selbstverständigungsdebatten der jungen Bundesrepublik. Protestanten haben sich an ihnen mit großem Deutungs- und Gestaltungswillen beteiligt, und zwar in kirchlich-konfessionellem, individuellem und gesellschaftlichem Engagement. Daraus formt sich die spezifische Gestalt eines bundesdeutschen Nachkriegsprotestantismus. Die Studien in diesem Band dokumentieren systematische Fragestellungen, fachspezifische Erkenntnisinteressen und erste Einsichten einer interdisziplinären Forschergruppe, die sich in der Verschränkung von theologischen, zeithistorischen, juristischen und politikwissenschaftlichen Perspektiven mit der inneren Vielgestaltigkeit des Protestantismus, der Vielfalt seiner gesellschaftlichen Ausstrahlung und der Komplexität seiner eigenen Veränderungsdynamik befasst.

Inhaltsübersicht

Vorwort

\section{Einführung ins Thema}

Christian Albrecht/Reiner Anselm: Zur Erforschung des Protestantismus in den ethischen Debatten der Bundesrepublik Deutschland 1949-1989

\section{Grundlegende Fragestellungen}

Andreas Busch: Politische Mitwirkung des Protestantismus - Hans Michael Heinig: Protestantische Vorstellungen demokratischer Rechtserzeugung - Christiane Kuller: Der Protestantismus und die Debatten um den deutschen Sozialstaat Claudia Lepp: Der Protestantismus in den Debatten um gesellschaftliche Integration und nationale Identität - Christian Albrecht: Protestantische Kommunikationsformen - Reiner Anse/m: Individualisierungsprozesse als Referenzpunkt theologisch-ethischer Theoriebildung - Martin Laube: Die bundesrepublikanische Gesellschaft im Spiegel der theologischen Ethik

\section{Fallskizzen}

Stefan Fuchs: Politische Einflusswege des Protestantismus in der Bundesrepublik Deutschland bis zur Wiedervereinigung Tobias Schieder: Die Rechtfertigungsfähigkeit des Rechtsungehorsams - Felix Teuchert: Normativer Anspruch, theologische Deutung und soziologische Analyse. Die evangelische Akademie Hermannsburg-Loccum in den Debatten über die Integration der Ostvertriebenen in die westdeutsche Gesellschaft - Sabrina Hoppe: „Aber wir können doch nicht alle Leute, die zu diesen Dingen etwas zu sagen haben, mit heranziehen!« Das Netzwerk Friedrich Karrenbergs als exemplarisches protestantisches Netzwerk in der frühen Bundesrepublik - Teresa Schall: Kommunikation des Protestantismus. Wirkungen und Rückwirkungen von Rundfunkkommentaren zum Kirchentag 1969 auf das mediale Bild des Protestantismus - Philipp Stoltz: Tische statt Huthaken. Werner Simpfendörfers Konzeption des »baulichen Provisoriums« als Modell protestantischer Verantwortung in der Gesellschaft - Sarah Jäger: Individualisierung als Herausforderung. Der Protestantismus vor Fragen von Sittlichkeit, Sexualethik und Geschlecht in den 1950er und 1960er Jahren - Hendrik Meyer-Magister: Individualisierung als Nebenfolge. Das Engagement des Protestantismus für die Kriegsdienstverweigerung in den 1950er Jahren - Georg Kalinna: Die 'Obrigkeitsdebatte' als Bewährungsprobe protestantischer Tradition. Das evangelische Staatsverständnis in der Bundesrepublik der 1950er und 1960er Jahre zwischen Wandel und Beharrung

IV. Ausblick

Christian Albrecht/Reiner Anse/m: Der bundesdeutsche Nachkriegsprotestantismus - Erste Umrisse

Christian Albrecht Geboren 1961; Professor für Praktische Theologie an der Evangelisch-Theologischen Fakultät der LudwigMaximilians-Universität München.

https://orcid.org/0000-0003-3465-5585

Reiner Anselm Geboren 1965; Professor für Systematische Theologie mit Schwerpunkt Ethik an der EvangelischTheologischen Fakultät der Ludwig-Maximilians-Universität München. https://orcid.org/0000-0003-4472-8303

Jetzt bestellen:

https://mohrsiebeck.com/buch/teilnehmende-zeitgenossenschaft-9783161539138?no cache=1

order@mohrsiebeck.com

Telefon: +49 (0)7071-923-17

Telefax: $+49(0) 7071-51104$ 